\title{
The Effect of Allergic Rhinitis on Quality of Life in Patients Suffering from the Disease: A Case Control Study
}

\author{
Ioannis D. Komnos' ${ }^{1}$, Maria C. Michali', Asimakis D. Asimakopoulos², Lentiona V. Basiari'1, \\ Ioannis G. Kastanioudakis ${ }^{{ }^{*}}$
}

${ }^{1}$ Department of Otorhinolaryngology, Faculty of Medicine, School of Medical Sciences, University Hospital of Ioannina, Ioannina, Greece

${ }^{2}$ Department of Otorhinolaryngology, Hospital Center of Luxembourg, Luxembourg City, Luxembourg

Email: j.d.komnos@gmail.com,maria.ch.michali@gmail.com, aasimak@outlook.com, ledi_poli@hotmail.com,

*kastanioudakisi@gmail.com

How to cite this paper: Komnos, I.D., Michali, M.C., Asimakopoulos, A.D., Basiari, L.V. and Kastanioudakis, I.G. (2019) The Effect of Allergic Rhinitis on Quality of Life in Patients Suffering from the Disease: A Case Control Study. International Journal of Otolaryngology and Head \& Neck Surgery, 8, 121-131.

https://doi.org/10.4236/ijohns.2019.84014

Received: May 13, 2019

Accepted: June 17, 2019

Published: June 20, 2019

Copyright $\odot 2019$ by author(s) and Scientific Research Publishing Inc. This work is licensed under the Creative Commons Attribution International License (CC BY 4.0).

http://creativecommons.org/licenses/by/4.0/

\begin{abstract}
Background: Apart from nasal symptoms allergic rhinitis was associated with ocular or other symptoms affecting social and somatic activities or sleep. In the literature, only a few prospective studies regarding allergic rhinitis and holistic consideration of quality of life were reported. Methods: The aim of this case control study was to investigate prospectively the effect of allergic rhinitis on quality of life. 103 patients (50 males and 53 females) with mean age $30.8 \pm 13.4$ years, range 18 - 55 years, diagnosed with the disease with skin prick testing, were evaluated regarding quality of life by using the General Health Questionnaire-28, the Athens Insomnia Scale (AIS) and the mini Rhinoconjunctivitis Quality of Life Questionnaire. 50 participants without history or allergic symptoms during the last 12 months formed the control group. Independent sample t-tests were conducted to assess significant differences between patients with allergic rhinitis and controls regarding all the examined parameters concerning quality of life. Data was analyzed using Windows statistical package of SPSS version 18.0 (SPSS Inc., Chicago, IL, USA). Statistical significance was set a priori at 0.05 . Results: Dust mite, mixed grass and pollens were the most common allergens found in patients with allergic rhinitis. It was also observed that the examined patients showed statistically worse results concerning not only physical and social activities but also quality of sleep and nasal or other symptoms as compared to healthy controls $(\mathrm{p}<0.05)$. However there were no statistically significant differences regarding anxiety and severe depression between the examined groups $(p>$ 0.05). Conclusion: Allergic rhinitis negatively affected the quality of life especially the parameters that were related to psychosocial activities and sleep, which might have an impact on daily living.
\end{abstract}




\section{Keywords}

Quality of Life, Allergic Rhinitis, Questionnaire, Sleep Disorders, Physical and Social Activities

\section{Introduction}

Allergic rhinitis (AR) is an IgE-mediated inflammatory chronic disorder of the nasal mucosa caused by exposure to allergens [1] [2] which affects a significant percentage of population varying from $10 \%-35 \%$ among different countries [3]-[8] with an increasing trend over the last years attributed to higher environmental exposure to allergic factors, longer stay in closed spaces and other social or economic causes [9] [10] [11].

Nasal symptoms such as nasal congestion, watery rhinorrhea, nasal itching, sneezing and post-nasal drip, are primarily observed in patients with AR [12] [13]. Snoring or mouth breathing due to nasal obstruction, ocular itching, pain or tearing, cough, loss of taste or smell, or even hearing dysfunction might be secondary chronic or recurrent symptoms of allergic rhinitis which can lead to sleep disturbance, diurnal fatigue, irritability or sleepiness affecting emotional, physical, and social aspects of quality of life [12] [13] [14] [15].

The effect of AR in quality of life is difficult to be assessed. Perceptions of quality of life change dynamically and variations may be referred even between individuals [16]. Therefore many scales and instruments which include physical, psychological and social dimensions as determined by the World Health Organization (WHO) have been developed to quantify assessment of quality of life, in forms of specific validated questionnaires [17]. However, because of the fact that $\mathrm{AR}$ is a multifactorial disease that is correlated with both genetic and environmental factors, weather conditions, age and local cultural and ethnic aspects, there have been proposed certain modifications and versions of these questionnaires for different populations and age groups [3] [18] [19].

The purpose of this study was to investigate the effect of AR on quality of life, in Greek adults suffering from the disease. Nasal, ocular and other secondary symptoms of AR can cause great discomfort in daily activities influencing family, social and professional life. The current study tries to recognize the factors that affect the quality of life of patients with AR. The knowledge of how AR affects physical, mental and social status may assist the clinicians to better understand the impact of disease in patients' life and give new directions for treatment options.

\section{Methods}

\subsection{Patients}

The study was carried out from March 2018 to March 2019. One hundred and three patients with at least one or more symptoms of AR such as nasal itching, 
rhinorrhea, sneezing and nasal congestion met the inclusion criteria which include 1) moderate to severe allergic rhinitis according to AR and its Impact on Asthma (ARIA) guidelines [20], 2) chronic clinical manifestations of AR and 3) positive skin prick test, 4) age above 18 years old. Patients with a) other chronic diseases or comorbidities such as asthma, sinusitis, food or medication allergy that could alter the skin tests, b) unstable work/academic activity that could affect sleep and quality of life, c) mild AR, d) age less than 18 years old and e) reluctance to participate to the study, were excluded.

According to ARIA guidelines [20], sleep disturbance is one of the factors that reclassify the severity of AR from mild to moderate-severe. In order to have a more homogenous examined sample we decided to exclude patients with mild AR from the study as the effect in quality of life would be limited as compared to those patients with moderate to severe AR. We only included adults in our study as children with AR present differences as compared to adults especially concerning the comorbidities which would have affected our results. Fifty participants with no history of AR or other allergies formed the control group.

The study was approved by the ethical board of the University Hospital of Ioannina, Greece. All the participants were in agreement with the testing protocol and gave their informed consent for participation in accordance with our University's Medical School Institutional Review Board procedures.

\subsection{Materials and Methods}

All the patients that were enrolled in the study were requested to complete 3 questionnaires: The General Health Questionnaire-28 (GHQ-28), the Athens Insomnia Scale (AIS) and the mini Rhinoconjunctivitis Quality of Life Questionnaire (miniRQLQ). The GHQ-28 that was developed by Goldberg in 1978, translated and modified for the Greek population by Garyfallos et al. [21] included 12 questions investigating disorders related to somatic symptoms, anxiety, social dysfunction and severe depression. Each question had numeric scores ranging from 1 to 4 (the higher score indicated worse results).

The AIS questionnaire examined characteristics of sleep quality within the last month by using 8 questions which were marked with numeric scores from zero (good results) to three (worst results) [22]. The miniRQLQ [23] consisted of 14 questions covering 7 aspects of daily life (one question for physical functioning, one for social and emotional functioning, another one for sleep disorder, two questions for practical problems, three regarding rhinitis, three for eye symptoms and finally three questions concerning other symptoms). The participants were asked to rank the severity of disturbance within last months on a seven-point scale ( 0 no disturbance to 6 very severe disturbance).

Skin prick testing was performed with the use of 48 allergic extracts provided by BIAL-Aristegui, Italia, which included allergens such as mixed grass, plane (Platanus vulgaris), olive (Oleaeuropea), dust mite, pollens-dermatophytes, Aspergillus fumigates, mixed cockroach, animal epithelium (dog, cat, horse etc.), 
$\alpha$-lactalbumin ( $\alpha \mathrm{LA}), \beta$-lactoglobulin $(\beta \mathrm{LG})$ and casein [24]. The flare and wheal were evaluated 15-20 minutes after the test. The wheal was compared with the positive (histamine phosphate $2.75 \mathrm{mg} / \mathrm{ml}$ ) and negative control (glycerin saline). Test was regarded as positive if the wheal was equal to or larger to histamine control (or greater than $3 \mathrm{~mm}$ ) [25].

\subsection{Statistics}

For statistical analysis independent sample t-tests were conducted to assess significant differences between patients with allergic rhinitis and controls regarding all the examined parameters concerning quality of life. Data was analyzed using Windows statistical package of SPSS version 18.0 (SPSS Inc., Chicago, IL, USA). Statistical significance was set a priori at 0.05 .

\section{Results}

The AR group was composed of 50 males and 53 females. Their mean age was $30.8 \pm 13.4$ years (range 18 to 55 years). The controls were 19 males and $31 \mathrm{fe}$ males with a mean age of 26.1 years \pm 7.3 years (range 18 to 50 years).

The most common allergens that were found in the group of allergic rhinitis and are presented in Figure 1, were dust mite, mixed grass and pollens with $63.4 \%, 60.2 \%, 48.6 \%$ of patients testing positive, respectively (Figure 1 ).

Regarding the quality of life, GHQ-28 revealed that patients with AR had higher scores and therefore worse results than controls regarding not only somatic symptoms but also social activities. Specifically, AR patients were feeling greater pressure or pain in head and they were slower in executing tasks as compared to controls. However, as concerned to the examined parameters anxiety and severe depression, there were no statistically significant differences between AR and control groups (Table 1).

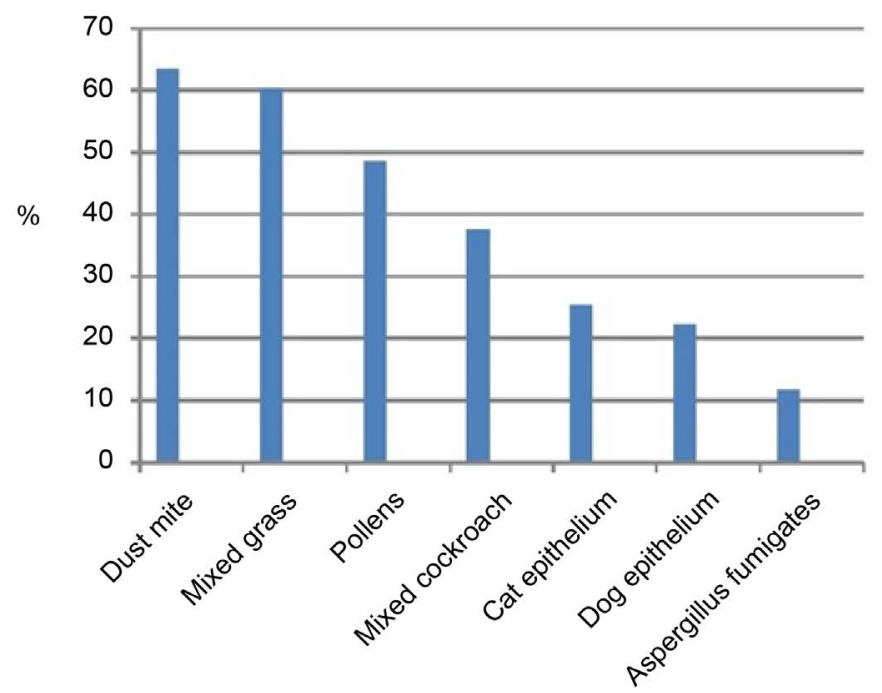

Percentage of Allergens

Figure 1. Percentage of most common allergens identified in AR patients with positive skin prick testing. 
Table 1. Statistically significant differences found between AR patients and controls with the use of modified GHQ-28 for the Greek population.

\begin{tabular}{lccc}
\hline \multicolumn{1}{c}{$\begin{array}{c}\text { Subcategories of modified GHQ-28 } \\
\text { (within last 2 weeks) }\end{array}$} & P-Value & $\begin{array}{c}\text { Patients with } \\
\text { AR. } \\
\text { Score of } \\
\text { answers } \\
\text { (mean } \pm \text { SD) }\end{array}$ & $\begin{array}{c}\text { Controls } \\
\text { Score of } \\
\text { answers } \\
\text { (mean } \pm \text { SD) }\end{array}$ \\
\hline $\begin{array}{l}\text { Feeling perfectly well and in good health } \\
\text { Feeling in need for a good tonic }\end{array}$ & $\mathrm{p}=0.027$ & $2.26 \pm 0.85$ & $1.68 \pm 0.45$ \\
$\begin{array}{l}\text { Feeling run down and out of sorts } \\
\text { Feeling that you are ill }\end{array}$ & $\mathrm{p}=0.03$ & $1.91 \pm 0.74$ & $1.14 \pm 0.40$ \\
$\begin{array}{l}\text { Getting any pains in your head } \\
\text { Feeling of tightness or pressure in your head }\end{array}$ & $\mathrm{p}<0.001$ & $2.20 \pm 0.82$ & $1.26 \pm 0.48$ \\
$\begin{array}{l}\text { Feeling nervous or under strain } \\
\text { Taking longer over the things you do }\end{array}$ & $\mathrm{p}<0.001$ & $2.12 \pm 0.99$ & $1.36 \pm 0.54$ \\
$\begin{array}{l}\text { Feeling capable of making decisions } \\
\text { about things }\end{array}$ & $\mathrm{p}<0.001$ & $2.12 \pm 0.61$ & $1.36 \pm 0.51$ \\
$\begin{array}{l}\text { Able to enjoy your normal day-to-day } \\
\text { activities }\end{array}$ & $\mathrm{p}<0.001$ & $2.17 \pm 0.61$ & $1.44 \pm 0.48$ \\
$\begin{array}{l}\text { Found that the idea of taking your own life } \\
\text { kept coming into your mind }\end{array}$ & $\mathrm{p}=0.015$ & $2.07 \pm 0.87$ & $1.42 \pm 0.33$ \\
$\begin{array}{l}\text { Feeling that you couldn't do anything } \\
\text { because your nerves were too bad }\end{array}$ & $\mathrm{p}=0.135$ & $1.05 \pm 0.27$ & $1.00 \pm 0.00$ \\
\hline
\end{tabular}

SD: Standard deviation.

With the use AIS questionnaire, it was also observed that quality of sleep was worse in patients with AR than in controls with the scores of this questionnaire being statistically higher in AR patients for all its subscales (Table 2).

Finally, the analysis of results from miniRQLQ unfolded that all aspects of this questionnaire (respecting physical and social functioning, quality of sleep, nasal, ocular or others symptoms such as fatigue, thirst and irritability) presented again statistically significant lower and consequently better scores in controls than in AR patients (Table 3).

\section{Discussion}

In the current study, it was observed that in patients with moderate to severe AR, there was a significant deterioration in nearly all the subjective factors that concern quality of life including physical, social and emotional parameters and sleep disorders as they were quantified with the use of worldwide applied questionnaires modified for the Greek population; and only the parameter severe depression was not influenced by AR symptoms. Moreover it was documented that dust mite, mixed grass and pollens were the most common allergens identified in our AR patients.

Similarly to our study, Juniper et al. [21] reported that AR symptoms were related with discomfort to patients and negative impact in quality of life in general. 
Table 2. Quality of sleep for AR patients and controls assessed with AIS questionnaire.

\begin{tabular}{lcc}
\hline \multicolumn{1}{c}{$\begin{array}{c}\text { Parameters of AIS Questionnaire } \\
\text { (within last month) }\end{array}$} & $\begin{array}{c}\text { Patients with AR } \\
(\text { mean } \pm \text { SD) }\end{array}$ & $\begin{array}{c}\text { Controls } \\
\text { (mean } \pm \text { SD) }\end{array}$ \\
\hline Sleep induction $\mathrm{p}<0.001$ & $1.93 \pm 0.58$ & $1.30 \pm 0.43$ \\
Awakenings during the night $\mathrm{p}<0.001$ & $2.04 \pm 0.99$ & $1.18 \pm 0.49$ \\
Final awakening $\mathrm{p}<0.001$ & $1.77 \pm 0.87$ & $1.06 \pm 0.44$ \\
Total sleep duration $\mathrm{p}=0.005$ & $1.68 \pm 0.60$ & $1.04 \pm 0.37$ \\
Sleep quality $\mathrm{p}=0.003$ & $1.70 \pm 0.71$ & $1.12 \pm 0.35$ \\
Well-being during the day $\mathrm{p}=0.001$ & $1.82 \pm 0.83$ & $1.25 \pm 0.36$ \\
Functioning capacity during the day $\mathrm{p}<0.001$ & $1.68 \pm 0.55$ & $1.10 \pm 0.22$ \\
Sleepiness during the day $\mathrm{p}=0.013$ & $1.85 \pm 0.76$ & $1.16 \pm 0.34$ \\
\hline
\end{tabular}

SD: Standard deviation.

Table 3. Comparison of quality of life between AR patients and controls according to miniRQLQ.

\begin{tabular}{lcc}
\hline \multicolumn{1}{c}{ Parameters of miniRQLQ (within last 2 weeks) } & $\begin{array}{c}\text { Patients with AR } \\
(\text { mean } \pm \text { SD })\end{array}$ & $\begin{array}{c}\text { Controls } \\
(\text { mean } \pm \text { SD })\end{array}$ \\
\hline Regular activities at home or work $\mathrm{p}<0.001$ & $2.68 \pm 1.63$ & $0.56 \pm 0.64$ \\
Social activities $\mathrm{p}<0.001$ & $2.38 \pm 1.71$ & $0.42 \pm 0.57$ \\
Sleep disorders $\mathrm{p}<0.001$ & $2.75 \pm 2.06$ & $0.70 \pm 0.90$ \\
Practical problems-Need for nasal or eye rub $\mathrm{p}<0.001$ & $3.14 \pm 1.96$ & $0.80 \pm 0.81$ \\
Practical problems-Need for nasal clearance $\mathrm{p}<0.001$ & $3.60 \pm 1.77$ & $0.58 \pm 0.88$ \\
Nasal symptoms-Sneezing $\mathrm{p}<0.001$ & $3.44 \pm 1.81$ & $0.71 \pm 0.79$ \\
Nasal symptoms-Congestion $\mathrm{p}<0.001$ & $4.01 \pm 1.70$ & $0.74 \pm 0.82$ \\
Nasal symptoms-Watery rhinorrhea $\mathrm{p}<0.001$ & $3.34 \pm 2.01$ & $0.56 \pm 0.74$ \\
Eye symptoms-Itching $\mathrm{p}<0.001$ & $1.98 \pm 1.11$ & $0.46 \pm 0.66$ \\
Eye symptoms-Pain $\mathrm{p}=0.002$ & $0.84 \pm 0.68$ & $0.18 \pm 0.31$ \\
Eye symptoms-Tearing $\mathrm{p}<0.001$ & $1.52 \pm 1.14$ & $0.34 \pm 0.47$ \\
Fatigue $\mathrm{p}<0.001$ & $1.56 \pm 1.59$ & $0.51 \pm 0.35$ \\
Thirst $\mathrm{p}=0.001$ & $1.08 \pm 0.85$ & $0.26 \pm 0.34$ \\
Irritability $\mathrm{p}<0.001$ & $1.46 \pm 1.18$ & $0.32 \pm 0.30$ \\
\hline
\end{tabular}

SD: Standard deviation.

In addition, Maspero et al. [26] and Schatz [27] found that AR had adverse effects on sleep, daily activities, physical, social and mental status. Association of AR symptoms with poor mental health, increased stress, depressed mood and work or social limitations was also found by Kim et al. [28] [29] and by Bhattacharyya [30] in a Korean and American study, correspondingly. Several studies documented that increased thirst and difficulties in concentrating were the most bothered situations in AR patients [31] [32], whilst others demonstrated that patients with AR were impaired in many domains of their daily lives [33] [34].

Particularly, regarding sleep disorders, an important factor that affects quality of life, Klossek M et al. displayed that nearly $60 \%$ of adults and almost $90 \%$ of 
children who suffered from AR presented sleep disturbances [35]. Furthermore, others studies indicated that nasal congestion which was considered by AR patients as their most troublesome symptom; was closely associated to their rhinitis-related sleep problems mainly due to breathing disorders during sleeptime which could cause, fragmented or partial sleep, sleepiness and consecutive tiredness, fatigue and irritability [2] [36]-[42]. Additionally, allergic symptoms such as sneezing, rhinorrhea and nasal pruritus along with different components of the immune and inflammatory response could also have an impact on sleep and daytime sleepiness impairing the quality of life [41].

In fact quality of life is considered to be negatively affected not only by the common symptoms of AR but also from the function of mediators such as histamine, leukotrienes (C4 and D4), interleukins (IL-1, IL-4, IL-5, and IL-6), prostaglandin D2 and inflammatory cytokine IFN- $\gamma$, that take part in the pathophysiology of the disease via modulation of central nervous system processes causing negative effects on the sleep-wake cycle and subsequently poor sleep quality [43] [44] [45].

Indeed regarding the obstructive sleep apnea, Cao et al. [46] reported that the prevalence of AR in obstructive sleep apnea (OSA) was considerably high and children with sleep-disordered breathing suffered from a higher incidence of AR than non-sleep-disordered breathing. However OSA adults accompanied with AR did not have any influences on sleep parameters [46].

In our study, we demonstrated that certain factors which quantify the quality of life of AR patients were impaired. We found that physical, psychological and social tasks were negatively affected in AR patients leading to limitations on daily activities and sleep but anxiety and severe depression were not influenced.

In order to add further validation in our study, apart from the clinical diagnosis of AR, we used skin prick testing. Thus, we also observed that the most common allergens found in the Greek population were dust mite, mixed grass and pollens frequently found in environments of Southern Europe [47] [48].

However, our study had several limitations. First of all, the concept of quality of life is somewhat subjective, varies among people and depends on the degree of individual expectations that might alter over time with the evolution of the disease. Therefore we tried to "measure the quality of life" by using scientifically recognized disease-specific questionnaires as recording tools. Secondly we included in our study only adults with moderate to severe AR. Although, AR concerns not only adults but also children or adolescents, we excluded these patients in order to have a more homogenous examined sample and to avoid possible difficulties in responding to questionnaire in such ages. Patients with mild AR were also excluded from the study as their symptoms would be insufficient to have an effect on their quality of life.

\section{Conclusion}

Conclusively, the results of the current study highlight that AR negatively affect 
not only the somatic but also social and emotional aspects of life, and especially sleep and wakening, impairing the quality of life of AR patients in general. This problem should be always taken into consideration by physicians who manage patient with AR in order to have a better outcome with the following treatment.

\section{Conflicts of Interest}

The authors have no conflicts of interest to disclose.

\section{Funding Source}

No funding was secured for this study.

\section{Financial Disclosure}

There are no financial relationships that could be broadly relevant to the work.

\section{References}

[1] Dykewicz, M.S. and Hamilos, D.L. (2010) Rhinitis and Sinusitis. Journal of Allergy and Clinical Immunology, 125, S103-S115. https://doi.org/10.1016/j.jaci.2009.12.989

[2] Bousquet, J., Khaltaev, N., Cruz, A.A., Denburg, J., Fokkens, W.J., Togias, A., et al. (2008) Allergic Rhinitis and Its Impact on Asthma (ARIA) 2008 Update (in Collaboration with the World Health Organization, GA(2)LEN and AllerGen). Allergy, 63, 8-160.

[3] Silva, C.H., Silva, T.E., Morales, N.M., Fernandes, K.P. and Pinto, R.M. (2009) Quality of Life in Children and Adolescents with Allergic Rhinitis. Brazilian Journal of Otorhinolaryngology, 75, 642-649. https://doi.org/10.1590/S1808-86942009000500005

[4] Pols, D.H., Wartna, J.B., Moed, H., van Alphen, E.I., Bohnen, A.M. and Bindels, P.J. (2016) Atopic Dermatitis, Asthma and Allergic Rhinitis in General Practice and the Open Population: A Systematic Review. Scandinavian Journal of Primary Health Care, 34, 143-150. https://doi.org/10.3109/02813432.2016.1160629

[5] Choi, S., Park, J.E., Li, S.S., Jung, H., Zi, M., Kim, T.H., et al. (2013) A Multicenter, Randomized, Controlled Trial Testing the Effects of Acupuncture on Allergic Rhinitis. Allergy, 68, 365-374. https://doi.org/10.1111/all.12053

[6] Keith, P.K., Desrosiers, M., Laister, T., Schellenberg, R.R. and Waserman, S. (2012) The Burden of Allergic Rhinitis (AR) in Canada: Perspectives of Physicians and $\mathrm{Pa}-$ tients. Allergy, Asthma \& Clinical Immunology, 8, 7. https://doi.org/10.1186/1710-1492-8-7

[7] Bauchau, V. and Durham, S.R. (2004) Prevalence and Rate of Diagnosis of Allergic Rhinitis in Europe. The European Respiratory Journal, 24, 758-764. https://doi.org/10.1183/09031936.04.00013904

[8] Brozek, J.L., Bousquet, J., Baena-Cagnani, C.E., Bonini, S., Canonica, G.W., Casale, T.B., et al. (2010) Global Allergy and Asthma European Network; Grading of Recommendations Assessment, Development and Evaluation Working Group. Allergic Rhinitis and Its Impact on Asthma (ARIA) Guidelines: 2010 Revision. Journal of Allergy and Clinical Immunology, 126, 466-476. https://doi.org/10.1016/j.jaci.2010.06.047

[9] Settipane, R.A. and Charnock, D.R. (2007) Epidemiology of Rhinitis: Allergic and 
Nonallergic. Clinical Allergy and Immunology, 19, 23-34.

[10] Hong, S.J., Ahn, K.M., Lee, S.Y. and Kim, K.E. (2008) The Prevalences of Asthma and Allergic Diseases in Korean Children. Korean Journal of Pediatrics, 51, 343-350. https://doi.org/10.3345/kjp.2008.51.4.343

[11] Jee, H.M., Kim, K.W., Kim, C.S., Sohn, M.H., Shin, D.C. and Kim, K.E. (2009) Prevalence of Asthma, Rhinitis and Eczema in Korean Children Using the International Study of Asthma and Allergies in Childhood (ISAAC) Questionnaires. Pediatric Allergy and Respiratory Disease, 19, 165-172.

[12] Bousquet, J., Van Cauwenberge, P., Khaltaev, N., Aria Workshop Group, World Health Organization (2001) Allergic Rhinitis and Its Impact on Asthma. Journal of Allergy and Clinical Immunology, 108, S147-S334.

https://doi.org/10.1067/mai.2001.118891

[13] IbiapinaCda, C., Sarinho, E.S., Camargos, P.A., Andrade, C.R. and Cruz Filho, A.A. (2008) Allergic Rhinitis: Epidemiological Aspects, Diagnosis and Treatment. The Jornal Brasileiro de Pneumologia, 34, 230-240.

[14] Juniper, E.F. (1997) Quality of Life in Adults and Children with Asthma and Rhinitis. Allergy, 52, 971-977. https://doi.org/10.1111/j.1398-9995.1997.tb02416.x

[15] Leynaert, B., Neukirch, C., Liard, R., Bousquet, J. and Neukirch, F. (2000) Quality of Life in Allergic Rhinitis and Asthma. A Population-Based Study of Young Adults. American Journal of Respiratory and Critical Care Medicine, 162, 1391-1396. https://doi.org/10.1164/ajrccm.162.4.9912033

[16] Carr, A.J., Gibson, B. and Robinson, P.G. (2001) Measuring Quality of Life: Is Quality of Life Determined by Expectations or Experience? BMJ, 322, 1240-1243. https://doi.org/10.1136/bmj.322.7296.1240

[17] Berlim, M.T. and Fleck, M.P. (2003) "Quality of Life": A Brand New Concept for Research and Practice in Psychiatry. The Revista Brasileira de Psiquiatria, 25, 249-252. https://doi.org/10.1590/S1516-44462003000400013

[18] Juniper, E.F., Howland, W.C., Roberts, N.B., Thompson, A.K., King, D.R. and Math, B. (1998) Measuring Quality of Life in Children with Rhinoconjunctivitis. Journal of Allergy and Clinical Immunology, 101, 163-170. https://doi.org/10.1016/S0091-6749(98)70380-X

[19] Borrego, L.M., Fonseca, J.A., Pereira, A.M., Pinto, V.R., Linhares, D. and Morais-Almeida, M. (2014) Development Process and Cognitive Testing of CARAT Kids-Control of Allergic Rhinitis and Asthma Test for Children. BCM Pediatrics, 14, 34. https://doi.org/10.1186/1471-2431-14-34

[20] Bachert, C. and Van Cauwenberge, P. (2003) The WHO ARIA (Allergic Rhinitis and Its Impact on Asthma) Initiative. Chemical Immunology and Allergy, 82, 119-126. https://doi.org/10.1159/000071546

[21] Garyfallos, G., Karastergiou, A., Adamopoulou, A., Moutzoukis, C., Alagiozidou, E., Mala, D., et al. (1991) Greek Version of the General Health Questionnaire: Accuracy of Translation and Validity. Acta Psychiatrica Scandinavica, 84, 371-378. https://doi.org/10.1111/j.1600-0447.1991.tb03162.x

[22] Soldatos, C.R., Dikeos, D.G. and Paparrigopoulos, T.J. (2000) Athens Insomnia Scale: Validation of an Instrument Based on ICD-10 Criteria. Journal of Psychosomatic Research, 48, 555-560. https://doi.org/10.1016/S0022-3999(00)00095-7

[23] Juniper, E.F., Thompson, A.K., Ferrie, P.J. and Roberts, J.N. (2000) Development and Validation of the Mini Rhinoconjunctivitis Quality of Life Questionnaire. Clinical \& Experimental Allergy, 30, 132-140. https://doi.org/10.1046/j.1365-2222.2000.00668.x 
[24] Gelardi, M., Marseglia, G.L., Licari, A., Landi, M., Dell'albani, I., Incorvaia, C., et al. (2015) Nasal Cytology in Children: Recent Advances. Italian Journal of Pediatrics, 38, 51. https://doi.org/10.1186/1824-7288-38-51

[25] Konstantinou, G.N., Bousquet, P.J., Zuberbier, T. and Papadopoulos, N.G. (2010) The Longest Wheal Diameter Is the Optimal Measurement for the Evaluation of Skin Prick Tests. International Archives of Allergy and Immunology, 151, 343-345. https://doi.org/10.1159/000250443

[26] Maspero, J., Lee, B.W., Katelaris, C.H., Potter, P.C., Cingi, C., Lopatin, A., et al. (2012) Quality of Life and Control of Allergic Rhinitis in Patients from Regions Beyond Western Europe and the United States. Clinical \& Experimental Allergy, 42, 1684-1696. https://doi.org/10.1111/j.1365-2222.2012.04025.x

[27] Schatz, M. (2007) A Survey of the Burden of Allergic Rhinitis in the USA. Allergy, 62, 9-16. https://doi.org/10.1111/j.1398-9995.2007.01548.x

[28] Kim, D.H., Han, K. and Kim, S.W. (2016) Relationship between Allergic Rhinitis and Mental Health in the General Korean Adult Population. Allergy, Asthma \& Immunology Research, 8, 49-54. https://doi.org/10.4168/aair.2016.8.1.49

[29] Kim, S.H., Won, H.K., Moon, S.D., Kim, B.K., Chang, Y.S., Kim, K.W., et al. (2017) Impact of Self-Reported Symptoms of Allergic Rhinitis and Asthma on Sleep Disordered Breathing and Sleep Disturbances in the Elderly with Polysomnography Study. PLoS ONE, 12, e0173075. https://doi.org/10.1371/journal.pone.0173075

[30] Bhattacharyya, N. (2012) Functional Limitations and Workdays Lost Associated with Chronic Rhinosinusitis and Allergic Rhinitis. American Journal of Rhinology \& Allergy, 26, 120-122. https://doi.org/10.2500/ajra.2012.26.3752

[31] Lu, D., Zhao, Y., Zheng, Y., An, P., Wang, L., Qiao, X., et al. (2011) Evaluation of Quality of Life Questionnaires for Adult Patients with Moderate to Severe Allergic Rhinitis. American Journal of Otolaryngology, 32, 494-498. https://doi.org/10.1016/j.amjoto.2010.09.014

[32] Valero, A., Mullol, J., Herdman, M., Rosales, M.J. and Spanish CQ7 Study Group (2011) Measuring Outcomes in Allergic Rhinitis: Psychometric Characteristics of a Spanish Version of the Congestion Quantifier Seven-Item Test (CQ7). Health and Quality of Life Outcomes, 9, 14. https://doi.org/10.1186/1477-7525-9-14

[33] Maurer, M. and Zuberbier, T. (2007) Under-Treatment of Rhinitis Symptoms in Europe: Findings from a Cross-Sectional Questionnaire Survey. Allergy, 62, 1057-1063. https://doi.org/10.1111/j.1398-9995.2007.01367.x

[34] Storms, W.W. (2004) Pharmacologic Approaches to Daytime and Night Time Symptoms of Allergic Rhinitis. Journal of Allergy and Clinical Immunology, 114, S146-S153. https://doi.org/10.1016/j.jaci.2004.08.045

[35] Klossek, J.M., Gohler, C., Vervloet, D., Deslandes, B., Dufour, X. and Neukirch, F. (2005) Epidemiology of Seasonal Spring-Time Allergic Rhinitis in Adults in France. La Presse Médicale, 34, 348-352. https://doi.org/10.1016/S0755-4982(05)83924-7

[36] Lunn, M. and Criag, T. (2011) Rhinitis and Sleep. Sleep Medicine Reviews, 15, 293-299. https://doi.org/10.1016/j.smrv.2010.12.001

[37] Storms, W. (2008) Allergic-Induced Nasal Congestion: Its Impact on Sleep Quality. Primary Care Respiratory Journal, 17, 7-18. https://doi.org/10.3132/pcrj.2008.00001

[38] Craig, T.J., Ferguson, B.J. and Krouse, J.H. (2008) Sleep Impairment in Allergic Rhinitis, Rhinosinusitis, and Nasal Polyposis. American Journal of Otolaryngology, 29, 209-217. https://doi.org/10.1016/j.amjoto.2007.06.002

[39] Leger, D., Annesi-Maesano, I., Carat, F., Rugina, M., Chanal, I., Pribil, C., et al. 
(2006) Allergic Rhinitis and Its Consequences on Quality of Sleep: An Unexplored Area. Archives of Internal Medicine, 166, 1744-1748. https://doi.org/10.1001/archinte.166.16.1744

[40] Colas, C., Galera, H., Anibarro, B., Soler, R., Navarro, A., Jauregui, I., et al. (2012) Disease Severity Impairs Sleep Quality in Allergic Rhinitis (The SOMNIAAR Study). Clinical \& Experimental Allergy, 42, 1080-1087.

https://doi.org/10.1111/j.1365-2222.2011.03935.x

[41] Thompson, A., Sardana, N. and Craig, T.J. (2013) Sleep Impairment and Daytime Sleepiness in Patients with Allergic Rhinitis: The Role of Congestion and Inflammation. Annals of Allergy, Asthma \& Immunology, 111, 446-451. https://doi.org/10.1016/j.anai.2013.05.020

[42] Meltzer, E.O. (2016) Allergic Rhinitis: Burden of Illness, Quality of Life, Comorbidities, and Control. Immunology and Allergy Clinics of North America, 36, 235-248. https://doi.org/10.1016/j.iac.2015.12.002

[43] Krouse, H.J., Davis, J.E. and Krouse, J.H. (2002) Immune Mediators in Allergic Rhinitis and Sleep. Otolaryngology_Head and Neck Surgery, 126, 607-613. https://doi.org/10.1067/mhn.2002.125300

[44] Tomassen, P., Vandeplas, G., Van Zele, T., Cardell, L.O., Arebro, J., Olze, H., et al. (2016) Inflammatory Endotypes of Chronic Rhinosinusitis Based on Cluster Analysis of Biomarkers. Journal of Allergy and Clinical Immunology, 137, 1449-1456. https://doi.org/10.1016/j.jaci.2015.12.1324

[45] Min, J.Y., Nayak, J.V., Hulse, K.E., Stevens, W.W., Raju, P.A., Huang, J.H., et al. (2017) Evidence for Altered Levels of IgD in the Nasal Airway Mucosa of Patients with Chronic Rhinosinusitis. Journal of Allergy and Clinical Immunology, 140, 1562-1571. https://doi.org/10.1016/j.jaci.2017.05.032

[46] Cao, Y., Wu, S., Zhang, L., Yang, Y., Cao, S. and Li, Q. (2018) Association of Allergic Rhinitis with Obstructive Sleep Apnea: A Meta-Analysis. Medicine (Baltimore), 97, e13783. https://doi.org/10.1097/MD.0000000000013783

[47] Vara, A., Fernández-González, M., Aira, M.J. and Rodríguez-Rajo, F.J. (2016) Fraxinus Pollen and Allergen Concentrations in Ourense (South-Western Europe). Environmental Research, 147, 241-248. https://doi.org/10.1016/j.envres.2016.02.014

[48] Papadakis, C.E., Kiagiadaki, D.E., Bonatos, S.I., Katotomichelakis, M., Danielides, V. and Proimos, E.K. (2016) Aeroallergens in West Crete, Greece: A Five Year (2010-2014) Aerobiological Study. European Archives of Oto-Rhino-Laryngology, 273, 1943-1949. https://doi.org/10.1007/s00405-016-3973-x 